\title{
Nuevos centros de urbanidad para Lima* Parque zonal Flor de Amancaes, Villa María del Triunfo Parque zonal Santa Rosa, Santa Rosa
}

\author{
New urban centers for Lima \\ Flor de Amancaes zonal park, Villa María del Triunfo \\ Santa Rosa zonal park, Santa Rosa
}

\author{
Aldo Facho** \\ Universidad Católica Santo Toribio de Mogrovejo \\ Recibido: 10 de mayo de 2019 \\ Aceptado: 18 de noviembre de 2019
}

\begin{abstract}
Partimos de la convicción de que la ciudad y la ciudadanía se construyen desde los espacios públicos, que éstos deben no solo organizar la trama urbana sino transformarse en lugares donde los ciudadanos se desarrollen y disfruten en igualdad.

(AFD+Abalosllopis, 2012)
\end{abstract}

Escribo este artículo a siete años de la convocatoria a concurso nacional de ideas para el nuevo parque zonal Flor de Amancaes por parte del Servicio de Parques de Lima (SERPAR), y cuatro años desde la finalización de las obras. Más que realizar una descripción del mismo, me interesa compartir las lecciones que aprendí del proceso de gestión y concreción.

En el año 2012 SERPAR convocó a un concurso para un nuevo parque zonal que se proyectaba construir en el distrito de Villa María del Triunfo, el mismo que ganamos junto a Ana Ábalos y Pablo Llopis de abalosllopis arquitectos. Este proyecto se enmarcaba en el Plan de Inversiones 2011-2014 que incluía la creación de dos nuevos parques y la implementación y remodelación de otros tres, con el objetivo de dotar a la población de equipamientos y servicios culturales, deportivos y recreacionales de alta calidad.

Luego de más de un año de gestiones que incluyeron la aprobación del Proyecto de Inversión Pública - PIP a nivel de Perfil y Factibilidad (siguiendo el Sistema Nacional de Inversión Pública - SNIP), en agosto de 2013 se convoca a través de UNOPS (Oficina de las Naciones Unidas de Servicios para Proyectos) a concurso público para la elaboración de los expedientes técnicos, la ejecución de la obra y el equipamiento (Concurso Oferta). Para este fin se diseñaron unos términos de referencia (TDR) que exigían un perfil de empresa contratista con amplia experiencia y solvencia en obras similares, así como un equipo técnico especializado para el desarrollo del expediente y acompañamiento de obra.

* Antecedentes del documento. Este artículo es el testimonio del autor sobre el diseño y la realización de dos parques zonales en Lima

** Aldo Facho Dede. Arquitecto y urbanista (Universidad Nacional de Ingeniería). Magister en desarrollo sustentable por la Universidad de Lanús (UNLA-FLACAM, Argentina). 
Atentos al proceso, presentamos los TDR a la empresa constructora ICCGSA (Ingenieros Civiles Contratistas Generales S.A.) quienes lo valoraron con interés y aceptaron presentarse a concurso con nosotros, como equipo técnico para la jefatura del desarrollo de los expedientes en las especialidades de Jefatura de Equipo, Arquitectura, Paisajismo y Museografía. En noviembre de ese año se dieron los resultados, quedando ICCGSA como ganadora de los nuevos parques zonales Flor de Amancaes y Santa Rosa.

En aquel entonces, según se nos informó, la meta era inaugurar los parques antes de finalizar la gestión municipal de la Sra. Susana Villarán, razón por la cual los tiempos de desarrollo del expediente y de la obra fueron muy cortos. Esto nos llevó a tener que convocar a diferentes equipos profesionales para poder cumplir con la meta exigida de tres meses para el expediente. Si bien el desarrollo del parque zonal Flor de Amancaes fue bastante fluido debido a que estuvimos presentes desde la concepción, no sucedió lo mismo con el parque zonal Santa Rosa. Este proyecto requirió un reajuste casi integral sobre la base del anteproyecto de SERPAR, con ajustes topográficos, funcionales, constructivos e incluso presupuestales, significando un esfuerzo mayor que asumimos en aras de la calidad final del proyecto.

Como era de esperar, fue físicamente imposible poder desarrollar los expedientes de todas las especialidades en tan corto tiempo, razón por la cual tuvimos que seguir trabajando en la compatibilización, incluso habiendo iniciado la ejecución. Aquí fue fundamental la colaboración de los equipos técnicos de obra, profesionales probos que se esforzaron en hacer prevalecer la arquitectura sobre el resto de especialidades. Este trabajo coordinado siguió hasta el final de la obra del parque zonal Santa Rosa, debiendo destacar la participación del arquitecto Omar Sempertegui, quien asumió el reto de cuidar la calidad del proyecto con alta profesionalidad. No se tuvo similar suerte en el parque zonal Flor de Amancaes, pues a mitad de proceso asumieron nuevos responsables con otro tipo de prioridades.

El proceso natural de elaboración del expediente y obra, llevaron a que ambos par- ques estuvieran a mitad de ejecución para finales de 2014. En enero de 2015 el Sr. Luis Castañeda asumió la dirección de la Municipalidad de Lima y, como es costumbre, renovó a los responsables de las diferentes gerencias, entre ellos a los de SERPAR. Lamentablemente la visión de ambas gestiones sobre los parques zonales tenía mercadas diferencias, generándose importantes modificaciones que alteraron el sentido original de los mismos.

En el caso del parque zonal Santa Rosa estos cambios afectaron menos en la lectura integral dada la amplitud del terreno (cerca de 30 hectáreas), pero en el caso de Flor de Amancaes se generaron recortes de materialidad, acabados y equipamientos que afectaron seriamente la calidad y capacidad de servicio, especialmente la del edificio del Centro Cultural (CREA). Además, se redujo significativamente la superficie del parque central al sustituir la laguna ornamental por unas piscinas recreativas de grandes dimensiones.

Aun así el saldo es positivo, pues los vecinos de ambos distritos han ganado un paquete de importantes equipamientos y servicios que han mejorado significativamente su calidad de vida urbana, acercándoles más al disfrute de sus derechos ciudadanos.

\section{Concepción urbanística}

Ambos proyectos fueron pensados para ser polos de urbanidad, pues están ubicados en zonas en proceso de consolidación que demandaban equipamientos y servicios que den escala al espacio urbano y sirvan como referentes para su desarrollo.

En el caso del parque zonal Santa Rosa, modelamos el terreno generando una sucesión de terrazas organizadas por un sistema de rampas y paseos. Propusimos la entrada principal a través de la plaza frente al edificio del polideportivo, desde la cual se puede acceder a los espacios deportivos al aire libre, a la piscina techada y a lo que originalmente fue un campo de fútbol, que se terminó sustituyendo por piscinas recreativas y una plaza de comidas. Desde esta plaza se puede apreciar la forma sinuosa de los edificios del Centro Cultural (CREA), y la cubierta tensada que resguarda la plaza. Entre el conjunto deportivo y el CREA desarrollamos junto 
al arquitecto Rafael Zamora un interesante proyecto paisajístico, buscando generar áreas de estar, contemplación y sombra, a la par que acompañábamos la pendiente con suaves rampas. A la plaza del CREA le seguía la plaza de las ferias y los huertos urbanos, que fueron suspendidos por el hallazgo de restos arqueológicos. Finalmente, en el extremo oeste del parque ubicamos el anfiteatro abierto, que acomodamos a la topografía para reducir el impacto en el movimiento de suelos. El conjunto está vinculado por un sistema de paseos y plazas que va acompañado de iluminación, arbolado y mobiliario.

En el caso del parque zonal Flor de Amancaes, el análisis del entorno inmediato y la complejidad de la trama urbana nos revelaron que, si bien el parque no posee la superficie de los grandes parques zonales, la dimensión de sus edificios superaba la escala de su entorno. Esta condición, sumada a su buena accesibilidad a través de la articulación de la avenida 27 de diciembre con la avenida Pachacútec y la Línea 1 del Metro de Lima, convirtió a este parque en una nueva centralidad urbana, estimulando el desarrollo económico local y la generación de nuevos servicios.

Trabajamos sobre el concepto que la ciudad debía disolverse en el parque y el parque construirse hacia la ciudad. Imaginamos un gran espacio abierto y continuo articulado por los edificios, que tomando las tensiones espaciales de la ciudad, las canalizan hacia el corazón del parque. Así, de manera centrífuga, el juego de los volúmenes construidos debía crear plazas perimetrales que, diluyéndose entre ellos alcanzan el gran parque central arbolado. Éstos espacios urbanos llevan el nombre de los edificios que los presiden: el Centro Cultural(CREA) genera la Plaza y el Paseo de las Culturas, pensados como expansión del mismo; la Plaza de los Deportes se conforma por el polideportivo techado y el bikepark, siendo un gran espacio lúdico y cívico complementario a sus usos; la Plaza de los Niños se asocia a los dos colegios existentes y al nuevo programa de la ludoteca, transformándose en un espacio infantil equipado con módulos de juegos al aire libre. Finalmente la Plazuela de las Flores organizada en torno al vivero, concluye la calle Pizarro y da continuidad a la avenida Independencia con la avenida de los Incas.

\section{Materialidad}

Los edificios de ambos parques debían cumplir con las siguientes características: ser de fácil ejecución, tener bajo costo de mantenimiento, ser pensados para resistir el uso intensivo y hasta actos vandálicos. Pensamos que el mejor material para su construcción era el hormigón armado, que decidimos acompañar con bloquetas y celosías de concreto. Para los cerramientos superiores decidimos utilizar paneles tarrajeados y solaqueados. Todos los materiales fueron pensados cara-vistas. Para los edificios del parque zonal Flor de Amancaes habíamos propuesto unas celosías triangulares que llevarían unas mamparas de vidrio detrás. Ya en el proceso de desarrollo del expediente, vimos que era una solución costosa pues obligaba a colocar mamparas en todos los edificios, por lo que se nos ocurrió diseñar una celosía a medida de un block de vidrio estándar de $19 \times 19$. De esta forma resolvimos el control solar, cerramiento traslúcido y lenguaje del edificio con dos elementos. En los equipamientos deportivos dejamos las últimas filas de celosías libres por ventilación y en los edificios de servicios mantuvimos la idea original de colocar la mampara detrás.

\section{Diseño paisajístico}

Ambos proyectos tuvieron como premisa el hecho de resolver un parque en el desierto. Las especies arbóreas y plantares debían ser de fácil adaptación al lugar y bajo consumo hídrico. De base descartamos la idea de una gran alfombra de césped, que como sabemos demanda grandes cantidades de agua para su arraigo y mantenimiento. Como alternativa organizamos funcionalmente el parque, identificando zonas de contemplación, zonas de descanso y zonas de actividad. Para las primeras utilizamos cubre-suelos y plantas de colores, para las segundas nos decidimos por el césped y para las terceras propusimos suelo natural estabilizado. Todo acompañado de árboles de diferentes especies que generarán espacios de sol y sombra. En ambos parques se construyeron e implementaron plantas de tratamiento residual (PTAR) para generar agua de riego. 


\section{Parques que forman ciudadanos}

Ser ciudadano es desarrollar el sentido de identidad y pertenencia al lugar donde interactuamos socialmente, para ejercer derechos y obligaciones. (Zucchetti, SERPAR, 2014, p. 28)

El edificio emblemático de ambos proyectos es el que albergaría el CREA (Centros de cultura, recreación y educación ambiental), no tanto por su dimensión, sino por su significado en relación al objetivo social que debían tener los parques zonales. Fueron ideados como equipamientos culturales para el desarrollo ciudadano, contando con servicios como biblioteca, auditorio, salas de usos múltiples, talleres, salones para exposiciones temporales y permanentes, área de niños (ludoteca), cafetería, entre otros. Dentro de los alcances del expediente técnico estaba el desarrollo de la museografía para las salas permanentes y temporales, debiendo desarrollarse sobre temas relacionados al lugar y su gente. El arquitecto Juan Carlos Burga desarrolló el guión museográfico para el parque zonal Santa Rosa sobre el tema "Entre el desierto y el mar", teniendo como objetivo comunicar a los visitantes el valor ambiental de la costa peruana. Para el parque zonal Flor de Amancaes la curadora Giuliana Vidarte propuso trabajar sobre las culturas originarias de la zona para la exposición permanente (a propósito del sitio arqueológico Tablada de Lurín), y sobre la construcción social del distrito de Villa María del Triunfo para la temporal. Lamentablemente ambas propuestas museográficas fueron descartadas por los funcionarios de SERPAR en la gestión municipal del Sr. Castañeda.

\section{Referencias bibliográficas}

AFD+Abalosllopis (2012) Memoria para el concurso de ideas para el Parque Zonal Flor de Amancaes. Lima, inédito.

Aristóteles (1933) Política. Madrid, España: Nueva Biblioteca Filosófica.

\section{A modo de reflexión final}

El derecho a la ciudad se manifiesta como forma superior de los derechos: el derecho a la libertad, a la individualización en la socialización, al hábitat y al habitar. (Lefebvre, 1978, p. 159)

La ciudad de Lima ha crecido las últimas décadas sin seguir un plan de desarrollo que ayude a organizar el proceso de urbanización, buscando equilibrar la dotación de servicios y equipamientos para garantizar estándares mínimos de calidad de vida para sus ciudadanos. Esto se torna crítico en los distritos periféricos pues gran parte de su crecimiento ha sido mediante la consolidación de invasiones, lo cual no ha permitido planificar un sistema de áreas libres, paisajísticas y recreativas que sumen al desarrollo de la población. En este contexto, los parques zonales cumplen un rol fundamental, pues no solo están llamados a dotar de áreas verdes y recreativas, sino deben sobre todo ser equipamientos para la construcción ciudadana; es decir, deben ofrecernos espacios para nuestro desarrollo tanto físico como intelectual y cultural.

Las grandes obras de la ciudad no pueden estar sujetas a los vaivenes políticos. Como ciudadanos, debemos exigir una visión estratégica de desarrollo urbano que trascienda los períodos de gobierno municipal y permita proyectar políticas a medio y largo plazo. Recién en ese momento podremos hablar de la construcción de una Lima para todos, pensada desde la igualdad, el desarrollo equilibrado y al servicio de la calidad de vida de sus ciudadanos.

Si toda agrupación tiende al bien, la ciudad o sociedad política, que es la superior entre ellas y las comprende todas, tiende al bien en mayor grado que las demás, y al mejor bien. (Aristóteles, 1933)

Lefebvre, H. (1978 [1968]) El derecho a la ciudad. BarceIona, España: Edicions 62.

Zucchetti, A., edición general (2014) La revolución de los parques. Lima, Perú: SERPAR. 


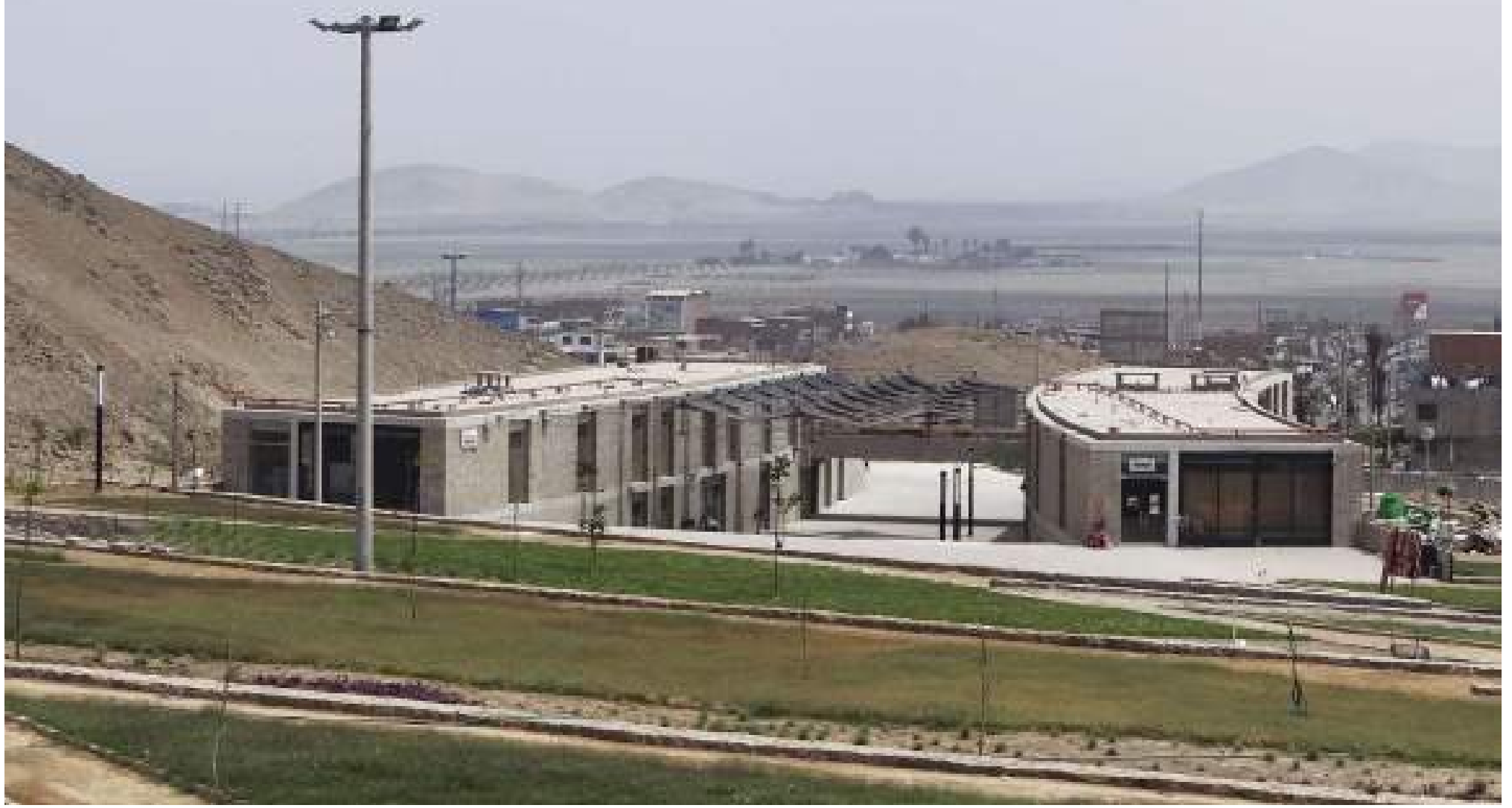

Parque zonal Santa Rosa. FD ARQUITECTOS S.A.C. Foto Aldo Facho.

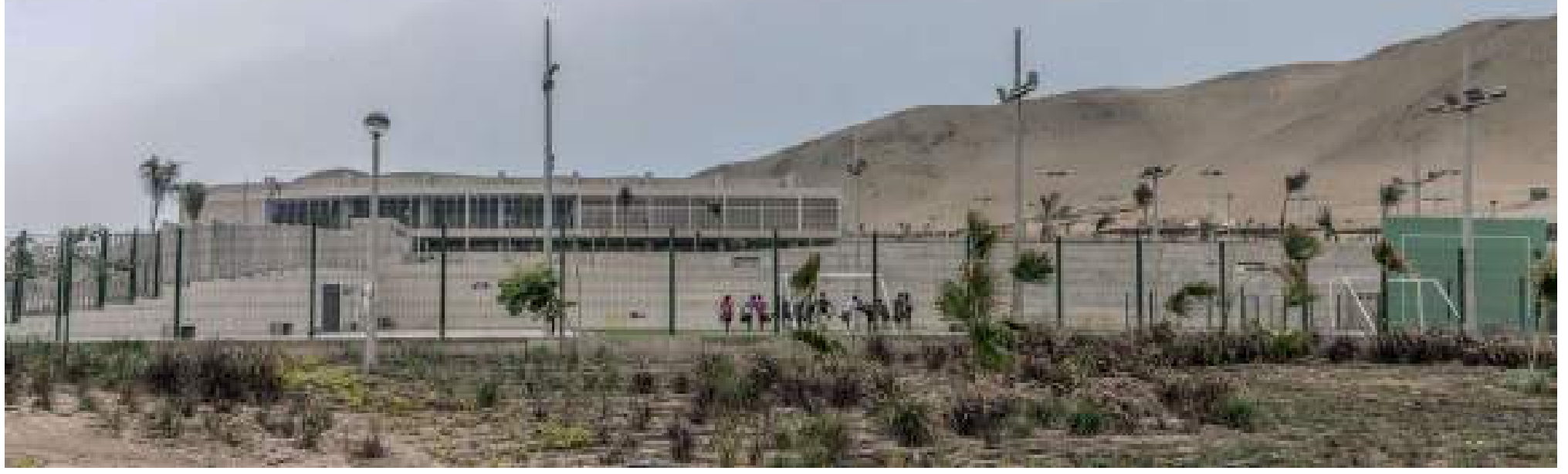

Parque zonal Santa Rosa. FD ARQUITECTOS S.A.C. Foto Eleazar Cuadros 


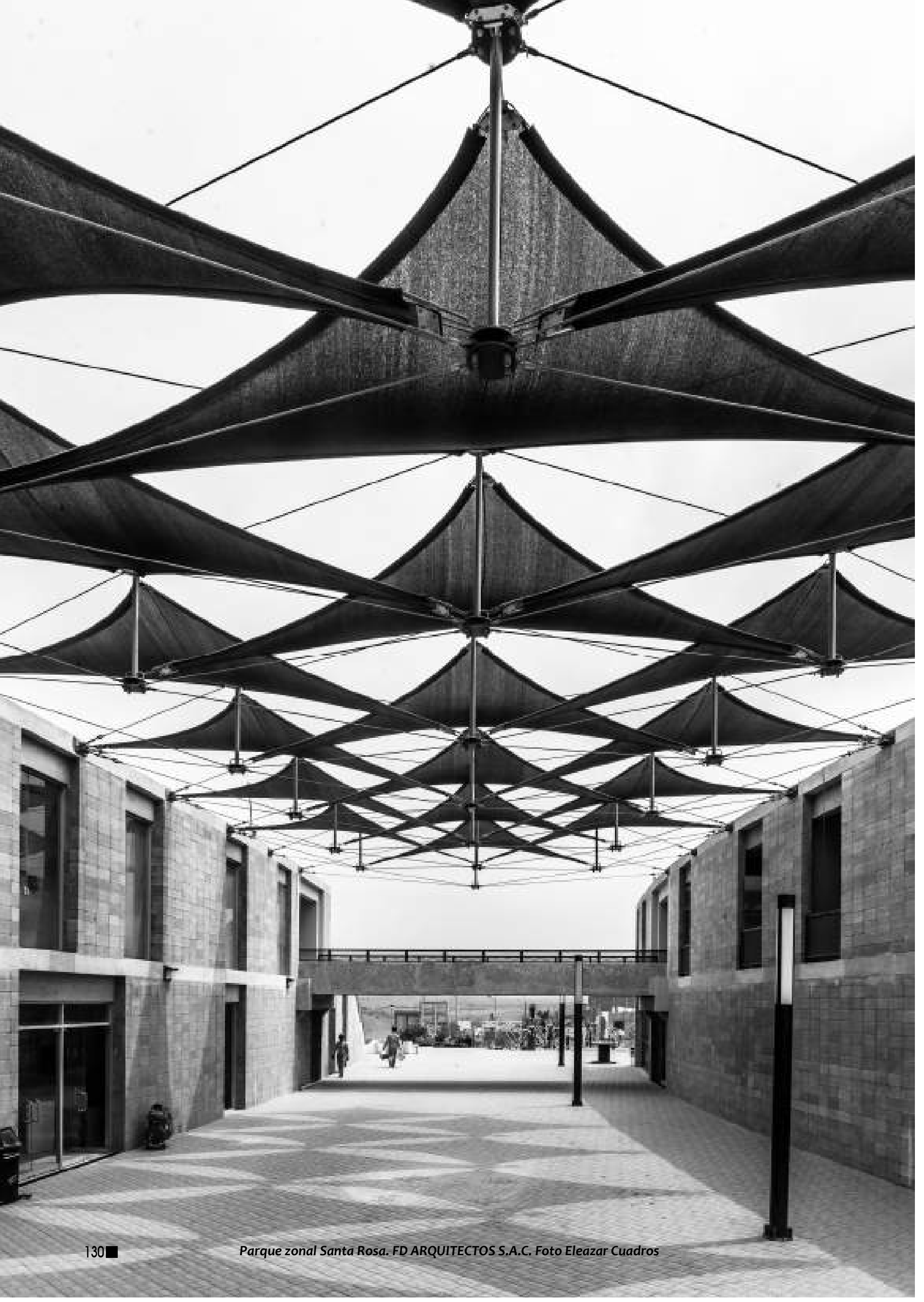




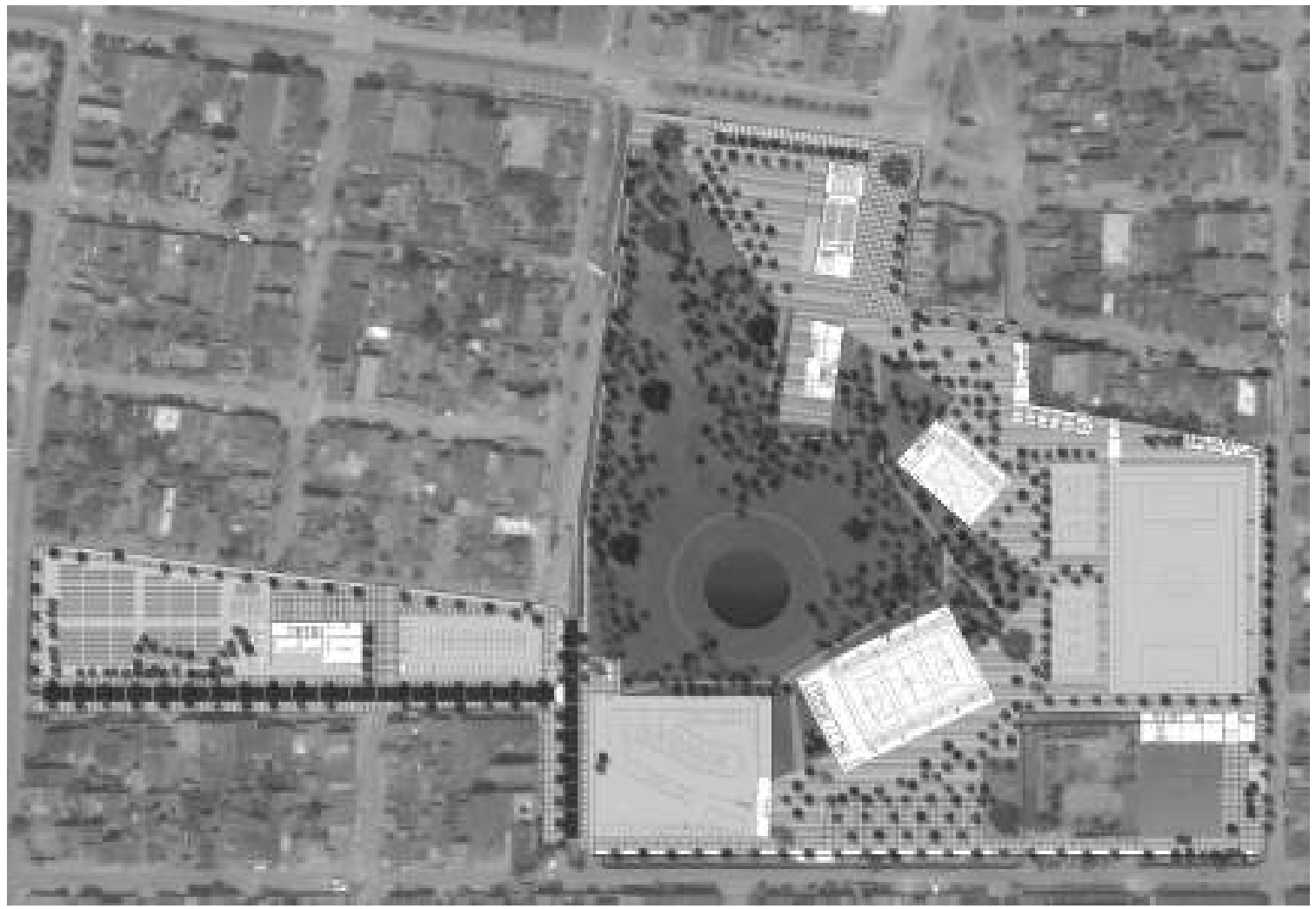

Parque Zonal Flor de Amancaes. Villa María del Triunfo. Lima. Planta general. Área total del terreno: $74,163.85 \mathrm{~m}^{2}$. Área ocupada: 10,638.74 $\mathrm{m}^{2}$

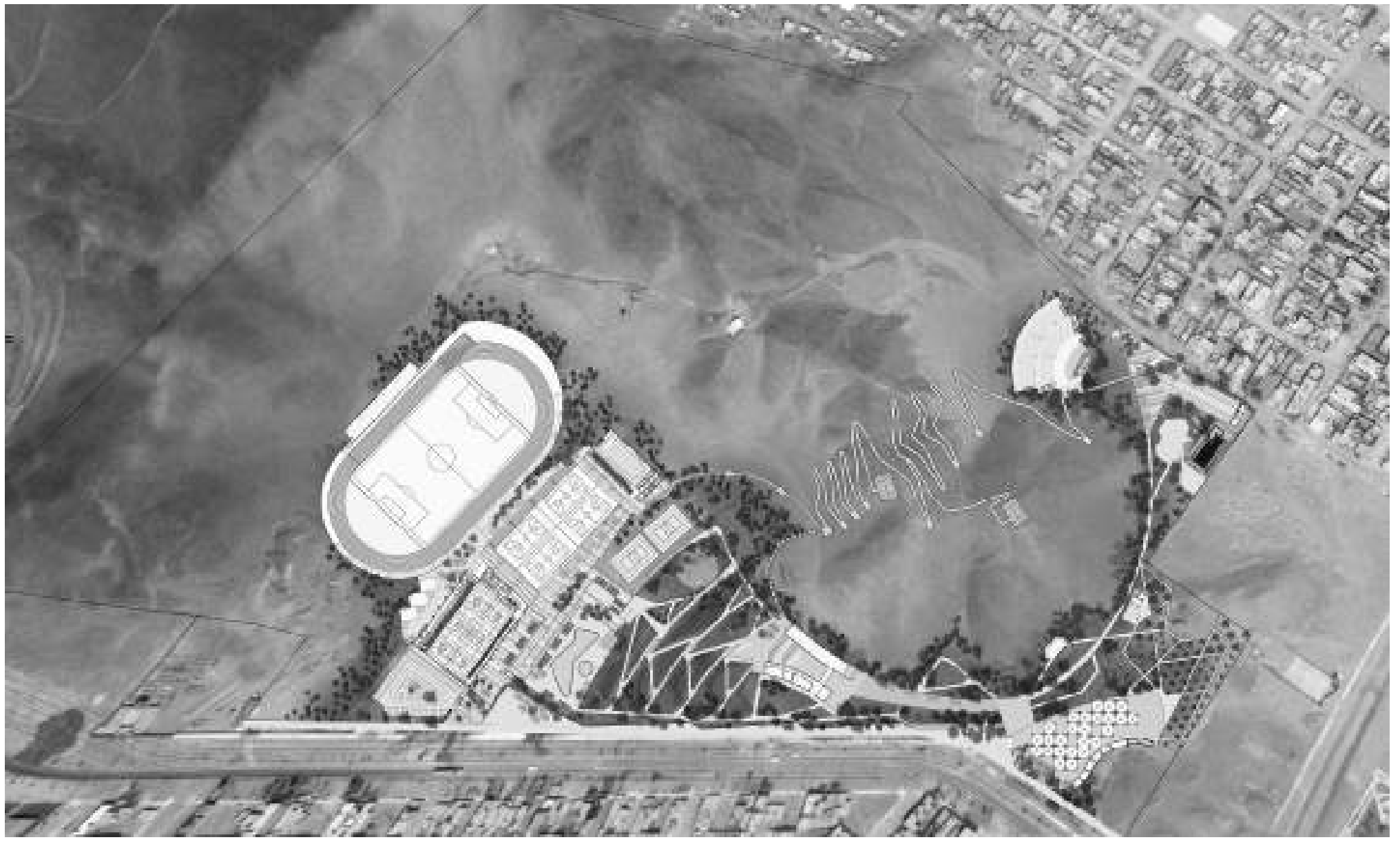

Parque Zonal Santa Rosa. Santa Rosa. Lima.

Planta general. Área total del terreno: 298,464.35 m². Área ocupada: 9,921.85 m² 


\section{FICHA TÉCNICA}

\section{PARQUE ZONAL FLOR DE AMANCAES}

\section{Resumen de áreas}

Área total del terreno: $74,163.85 \mathrm{~m} 2-100 \%$

Área libre (Parques, plazas, paseos, losas y campo deportivo): 63,525.11m2 - 86\%

Área ocupada: 10,638.74m2-14\%

Área total construida: $13,035.04 \mathrm{~m} 2$

Empresa responsable la elaboración del expediente técnico, construcción y equipamiento: CONSORCIO PARQUES DE LIMA (ICCGSA/KUKOVA INGENIEROS S.A.C.)

\section{Elaboración del expediente técnico:}

Jefe de equipo: Arq. Carlos Alberto Fernández Dávila

Proyecto y coordinación general: FD ARQUITECTOS S.A.C.

Arq. Aldo Facho Dede, Arq. Luis Felipe Díaz, Arq. Rosa Elena Fernández Dávila.

Desarrollo de arquitectura: Arq. Carlos Callupe, Arq. Peter Seinfeld, Arq. María Paz Ballén. Colaboradores: Arq. Alejandro Solórzano, Arq. Carlos Navarro, Arq. Gustavo Díaz, Arq. Marius Ege, Bach. Arq. Julio Cabrera, Sr. Diego Célis, Sr. Erick Tapia.

Proyecto paisajista: Arq. Bárbara Montoro Proyecto museográfico: Lic. Giuliana Vidarte Anteproyecto: Aldo Facho Dede + Abalosllopis arquitectos (Pablo LLopis, Ana Ábalos). Proyecto de ingenierías y mobiliario: KUKOVA INGENIEROS S.A.C.

\section{PARQUE ZONAL SANTA ROSA}

\section{Resumen de áreas}

Área total del terreno: 298,464.35m2-100\%

Área libre (área natural no intervenida, parques, plazas, paseos, losas y campo deportivo): $288,542.50 \mathrm{~m} 2-99.967 \%$

Área ocupada: 9,921.85m2 - 0.033\%

Área total construida: $11,852.42 \mathrm{~m} 2$

\section{Empresa responsable la elaboración del expediente técnico, construcción y} equipamiento: CONSORCIO PARQUES DE LIMA (ICCGSA/KUKOVA INGENIEROS S.A.C.)

Elaboración del expediente técnico:

Jefe de Equipo: Arq. Manuel Zubiate

Proyecto y coordinación general: FD ARQUITECTOS S.A.C.

Arq. Carlos Alberto Fernández Dávila, Arq. Aldo Facho Dede, Arq. Luis Felipe Díaz,

Arq. Rosa Elena Fernández Dávila.

Desarrollo de arquitectura: Arq. Carlos Callupe, Arq. Peter Seinfeld, Arq. María Paz Ballén. Colaboradores: Arq. Alejandro Solórzano, Arq. Carlos Navarro, Arq. Gustavo Díaz, Arq. Marius Ege, Bach. Arq. Julio Cabrera, Sr. Diego Célis, Sr. Erick Tapia.

Proyecto paisajista: Arq. Rafael Zamora

Proyecto museográfico: Arq. Juan Carlos Burga

Proyecto de ingenierías y mobiliario: KUKOVA INGENIEROS S.A.C.

Arquitecto responsable de obra: Arq. Omar Sempertegui 